\title{
Matching Organization Personality Perceptions and the Job Applicant's Personality: A Correlational Study
}

James Dakota Green

Portland State University

Follow this and additional works at: https://pdxscholar.library.pdx.edu/mcnair Let us know how access to this document benefits you.

\section{Recommended Citation}

Green, James Dakota (2011) "Matching Organization Personality Perceptions and the Job Applicant's Personality: A Correlational Study," PSU McNair Scholars Online Journal: Vol. 5: Iss. 1, Article 14. https://doi.org/10.15760/mcnair.2011.1 
Portland State University McNair Research Journal 2011

Matching Organization Personality Perceptions and the Job Applicant's Personality: A Correlational Study

by
James Dakota Green

Faculty Mentor:

Donald M. Truxillo

Citation: Green, James Dakota. Matching Organization Personality Perceptions and the Job Applicant's Personality: A Correlational Study Portland State University McNair Scholars Online Journal, Vol. 5 
Running head: MATCHING ORGANIZATION PERSONALITY PERCEPTIONS

Matching Organization Personality Perceptions and the Job Applicant's Personality: A Correlational Study

James Dakota Green

Faculty Mentor: Donald M. Truxillo, PhD

Portland State University

I would like to thank Dr. Donald M. Truxillo for supervision of this project which was completed with support from a McNair scholarship. I also thank Josh Carlsen for his assistance with data collection.

Correspondence should be addressed to Dakota Green, and should be sent electronically to jdg@pdx.edu 


\begin{abstract}
Recruitment is the process by which organizations acquire the talent they need to be effective. As recruitment becomes more competitive, organizations need to attract the types of job applicants that best fit their needs. Recently, researchers have suggested that human resources departments adopt strategies that are similar to marketing strategies; specifically, it has been suggested that organizations can be characterized as having an organizational "personality,” and that the personality of an organization can be leveraged to attract the best applicants. Organizational personality is described similarly to brand personality and is defined as the human characteristics attributed to an organization. This research examines the relationship between organization personality perceptions and the personality of potential job applicants, that is, which type of applicant is attracted to which type of organization. Participants rated the attractiveness of 33 trait adjectives in a potential employer and then rated their own personalities in terms of Big Five and proactive personality models. Results suggest that the attractiveness of an organization's perceived personality was related to the personality of the participant. Suggestions for future research are presented, and findings may be used to better understand which types of organizations are most attractive to which applicants.
\end{abstract}

Keywords: organizational personality, proactive personality, Big Five personality, recruitment. 
Matching Organization Personality Perceptions and the Job Applicant's Personality: A Correlational Study

Talented applicants are necessarily scarce. The success of a human resources department in recruiting talented applicants has been demonstrated to provide sustainable competitive advantage (Barney, 1986). Companies spend approximately 31\% of the human resources budget is spent on recruitment and retention efforts (Leonard, 1999). In procuring the most talented applicants, a firm is not only equipping themselves with good workers, but they are also holding talent that their competitors are not. Thus, it is worthwhile to pursue talent and determine the most effective ways to do so.

Cable and Turban (2001) have suggested that human resources departments should use a recruitment strategy that is similar to a marketing strategy. Slaughter and Greguras (2009) have suggested that an effective way to do this is to understand how organization personality perceptions, defined as "a set of human personality characteristics perceived to be associated with an organization” (Slaughter, Zickar, Highhouse, \& Mohr, 2004, p. 86), affect initial attraction. Slaughter et al. have recently developed a measure of organization personality perceptions, wherein five distinct dimensions categorize organizational personality: Boy Scout, Innovativeness, Dominance, Thrift, and Style.

Organizational personality is analogous to brand personality (Slaughter et al., 2004; Cable \& Turban, 2001). By imbuing brands with personalities, marketers are creating a medium for communicating to a designated consumer market. When a brand is well liked or successful, the result is brand consumption (Kapferer, 2004). Marketing scholars define the value consumers have for a brand as brand equity (Aaker, 1996). Cable and Turban have similarly defined recruitment equity as a company's ability to recruit talented job seekers based on how much they 
value the company. A human resources department is able to build recruitment equity by communicating in a way that reaches their target applicant market.

Schneider (1987) suggests that individuals are attracted to, select, and stay employed by organizations where they find similarity. This model is referred to as the attraction, selection, and attrition (ASA) model, which describes the process by which job seekers and organizations form mutually beneficial relationships. According to this model, there is a natural tendency for human beings to gravitate towards others with similar traits (Schneider). Thus, if an organization is attempting to recruit applicants, they should communicate directly to job seekers who find the organization’s personality attractive.

In order to reach an audience that will gravitate towards a particular organizational personality, research needs to evaluate not only the perceived personality of the organization, but also the potential relationship between the personality of job seekers and the organizational personality types they find attractive. Slaughter and Greguras (2009) have recently evaluated the affect of the relationship between respondents’ Big Five personality (Saucier, 1994) and organization personality perceptions on an applicant's initial attraction to an organization. However, this study assigned participants to specific organizations, which may have lead to bias effects because of other factors associated with a particular company such as compensation. Furthermore, Slaughter and Greguras did not examine the effects of proactive personality (Seibert, Crant, \& Kraimer, 1999), an important human personality characteristic found to affect a range of workplace outcomes.

The purpose of this study is to further examine the relationship between organization personality perceptions and Big Five personality. Additionally, the relationship between organization personality perceptions and proactive personality will be examined. 


\section{Marketing Context of Recruitment}

In the same way consumers differentiate brands based on images of the makers of a given product, users of the product, and of the product itself, job seekers differentiate organizations based on information about their products, the job itself, and the people who work for the organization (Cable \& Turban, 2001). An organization’s image has been defined as “an audience's beliefs about traits that are central, distinctive, and relatively enduring about the company” (Cable \& Yu, 2006, p.828). Cable and Turban have suggested that organizational images are analogous to brands; jobs are analogous to products; and job seekers are analogous to consumers (Cable \& Turban). The image that an individual has of a company is something that is derived from inferences individuals hold of the organization as a producer of products or services. Organizational image can be derived from any number of interactions that an individual has with a company, and these interactions will be the base for which individuals differentiate that company from its competitors (Cable \& Yu).

A company's brands are the careful craft of that company's marketing department. Marketing departments work fiercely to create brands that have a 'unique selling position' (Keller, 1993, p. 6). They do this by defining their target consumer within the market in which they intend to compete (Kotler, 1972). Effective brand construction leads to brand equity which in turn leads consumers to perceive a reason to choose a particular brand (Keller). Brand equity is defined as the value that consumers have for a brand, and this value is based on the consumer's knowledge of that brand (Aaker, 1996). Cable and Turban (2001) have similarly defined recruitment equity as the value job seekers have for an organization as a potential employer, based on knowledge that the job seeker has about that organization. Brand equity is considered to be an asset for companies: for some brands the equity is so high that brand 
recognition is ubiquitous, customer loyalty rates are at the top of the industry, and perceptions of quality are assumed (Aaker, 1991). If brand equity is analogous to recruitment equity (Cable \& Turban), then it is likely that firms stand to benefit a great deal from building recruitment equity. Devendorf and Highhouse (2008) have suggested that individuals will choose to work for companies where they believe they will fit in. Therefore, human resources departments will need to manage their organizational image in a way that allows their target applicant market to identify with the company as a good fit for employment. According to Devendorf and Highhouse there are two main explanations for applicants to be attracted to particular organizations:

The first reason that we might expect applicants to be attracted to organizations whose employees are similar to them is that similarity facilitates social interaction and provides a sense of comfort (Cable \& Turban, 2001), presumably from avoidance of disagreement (Berscheid \& Reis, 1998). People like to be liked, and similarity enhances expectations of mutual need gratification in the form of reciprocal liking (Condon \& Crano, 1988). A second reason to expect applicants to be attracted to organizations whose employees are similar to them is that people want to be seen with others who are like them. Social identity theory (SIT; Tajfel \&Turner, 1986) suggests that people tend to classify themselves and others into various social categories (e.g. organizational membership, religious affiliation). These categories are often defined by prototypical characteristics abstracted from the members (Ashforth \& Mael, 1989). Self-categorization (Turner, 1985) is the process by which people define themselves in terms of membership in social groups. When one identifies with a social group, this identification leads to activities that are congruent with the identity, support for institutions that embody the identity, and stereotypical perceptions of self and others (Ashforth \& Mael, 1989; Highhouse et al., 2007). (p.608) 
The tendency for individuals to define themselves according to where they work is similar to the tendency of consumers to choose brand names based on their value for the brand and their ability to select a branded product. When applicants base their judgments about the attractiveness of an organization on their perception of its image, they are assessing the value they place on the organization relative to the explanations given by Devendorf and Highhouse. Thus, it is important that companies establish their target applicant market and strengthen recruitment equity, as it will likely increase their effectiveness to recruit talent.

\section{Human Personality: The Big Five}

Human personality is often defined in terms of traits. These traits are assumed to be generally characteristic of an individual and their tendency to behave a certain way across situations (Levy, 2006). The Big Five model of normal personality is thought to have five distinct dimensions: Openness to Experience, Conscientiousness, Extraversion, Agreeableness, and Neuroticism (e.g. McCrae \& John, 1992). The Big Five model is the most widely used and researched measure of normal personality (Gosling, Rentfrow, \& William, 2003). While there has been variation in naming the five dimensions, it is generally accepted that the Big Five model is an effective tool for measuring normal human personality.

Each dimension of the Big Five model suggests different traits and tendencies for the individual. Individuals rating themselves as open to experience are thought to be imaginative, cultured, curious, original, broad-minded, intellectual, and artistically sensitive (Barrick \& Mount, 1991). They tend to prefer environments that allow them to learn new things (Barrick, Mount, \& Judge, 2001), that are unusual (Rolland, 2002), and that allow them to be creative and innovative (Crant \& Bateman, 2000). 
Those rating themselves as conscientious are generally considered careful, thorough, responsible, organized, planful, hardworking, achievement-oriented, and persevering (Barrick \& Mount, 1991). Individuals characterized by this dimension tend to be diligent, and have a strong will to achieve (McCrae \& John, 1992), they are persistent, in control of their impulses, and follow the rules Rolland, 2002).

Those who see themselves as extraverted tend to be sociable, gregarious, assertive, talkative, and active (Barrick \& Mount, 1991). These individuals tend to be dominant (McCrae \& John, 1992), charismatic (Crant \& Bateman, 2000), and value large social networks (Sutin, Costa, Miech, \& Eaton, 2009).

Individuals that rate themselves as agreeable are described as courteous, flexible, trusting, good-natured, cooperative, forgiving, soft-hearted, and tolerant (Barrick \& Mount, 1991). Agreeableness is characterized by a preference for work environments that encourage teamwork (Barrick et al., 2001) and social sensitivity (Crant \& Bateman, 2000), and they value characteristics such as altruism, nurturance, and emotional support (McCrae \& John, 1992).

Individuals that rate themselves as neurotic tend to be anxious, depressed, angry, embarrassed, emotional, worried, and insecure (Barrick \& Mount, 1991). These individuals tend to view reality as threatening (Barrick et al, 2001), fear novel situations, and prefer stable environments (Slaughter \& Greguras, 2009).

By evaluating personality, researchers are able to categorize the public into generalized tendencies and thus are able to predict general behavior. In the present study, the Big Five framework is used to evaluate how individual personality types vary in their attraction to different types of organizational personality.

Proactive Personality 
While there are many variations in ways of describing of personality, proactive personality as a trait tends to function in a way that is unlike the Big Five personality types. According to Bateman and Crant (1993) individuals with a proactive personality possess the tendency to pursue opportunities without allowing situational barriers to interfere with their goals. These individuals are more likely to manage their careers by pursuing opportunities that

allow them to perform most successfully (Seibert et al., 1999). They anticipate change (Bateman \& Crant), and they actively select, create, and shape their work environments (Seibert et al.; Crant, 1995). It has also been demonstrated that proactive personality is related to higher levels of career success (Seibert et al.). Individuals with proactive personality are valuable for companies because of their strong work ethic and commitment to their careers.

Individuals with proactive personalities will pursue opportunities that they believe will move them towards their goals. Proactive personality has been demonstrated to lead not only to career success, but also to career satisfaction (Seibert et al., 1999). These individuals value learning new skills and believe that the better they become in their careers the more successful they will be in the long run. Because these individuals are drawn to opportunities that advance their careers, they are likely to be drawn to organizations that are growing successfully or to organizations perceived as rigorous, demanding, reputable, dominant, or growing.

\section{Organization Personality Perceptions}

As noted earlier, organizational personality is one component of organizational image. An organization's personality is defined similarly to brand personality. Aaker (1997) defines brand personality as the "set of human characteristics associated with a brand" (p.347). Organizational personality is similarly defined as the set of human characteristics associated with an organization. Organization personality perceptions are beliefs held by job seekers regarding 
potential employers, based on perceived human characteristics. Slaughter et al. (2004) established a metric that describes organizational personality in terms of 33-trait adjectives and measures organizational attractiveness according to five organizational personality dimensions: Boy Scout (e.g. friendly), Innovativeness (e.g. exciting), Dominance (e.g. successful), Thrift (e.g. simple), and Style (e.g. hip). This metric is useful for measuring job seekers' initial attractiveness to organizations based on organizational personality and will be useful for understanding effective strategies for building recruitment equity.

The present study investigates the relationship between organization personality perceptions and an individual's Big Five personality and proactive personality. Specifically, this study investigates the degree to which people with different personalities are attracted to different types of organizational personalities. As mentioned above, this study varies from the study Slaughter and Greguras (2009) have recently conducted in two ways. First, the relationship between organizational personality perceptions and Big Five personality are independent of specific companies, and thus examine only the relationship between the two constructs. Second, this study examines the relationship between organization personality perceptions and proactive personality. This study proposes similar hypotheses as Slaughter and Greguras, in the attempt to retest the relationship between organizational personality perceptions and human personality using a different methodology. That is, I will examine the degree to which individuals with different personality types are attracted to different types of organizational personalities in a potential employer.

The Boy Scout dimension. The adjectives used to describe organizations perceived to be high on the Boy Scout dimension are friendly, family-oriented, pleasant, personal, attentive to people, helpful, honest, cooperative, and clean. Target, Disney, and Johnson and Johnson are 
examples of firms that are described by this dimension (Slaughter \& Greguras, 2009). These organizations are considered to be benevolent employers, and the people who work for these companies are considered to be kind, honest, and family-oriented (i.e. agreeable). Individuals that are team-oriented, softhearted, hard working, and responsible (i.e. conscientious) may find organizations that represent the Boy Scout dimension to be attractive.

Hypothesis $1(a-b)$ : Those who are more (a) agreeable and (b) conscientious will be more attracted to organizations strong in the Boy Scout dimension. Specifically, preference for the Boy Scout dimension will be correlated with (a) Agreeableness and (b) Conscientiousness.

The Innovativeness dimension. The adjectives used to describe organizations perceived to be high on the Innovativeness dimension are creative, exciting, interesting, unique, and original. IBM, PepsiCo, and Microsoft are examples of firms that are described by this dimension (Slaughter \& Greguras, 2009). Innovative companies tend to push research and development of new products continuously. These companies have a reputation of excellence and are growing as part of their business model. Individuals who are ambitious and hardworking (i.e. conscientious), those who value novel experiences and creativity (i.e. open to experience), and those who value growth opportunities (i.e. proactive) may be drawn to innovative organizations.

Hypothesis 2 (a-c): Those who are more (a) conscientious, (b) open to experience and (c) proactive will be more attracted to organizations strong in the Innovativeness dimension. Specifically, preference for the Innovativeness dimension will be correlated with (a) Conscientiousness, (b) Openness to Experience, and (c) Proactivity.

The Dominance dimension. The adjectives used to describe organizations perceived to be high on the Dominance dimension are successful, popular, dominant, busy, and active. CocaCola, General Motors, Disney, and AT\&T are examples of firms that are described by this 
dimension (Slaughter \& Greguras, 2009). Because these firms tend to be large corporations, they also tend to be very competitive and have strong histories of success. Individuals that value strong social networks (i.e. extravert) and opportunities to learn and advance through hard work (i.e. proactive) within the organization may be attracted to organizations characterized by the Dominance dimension.

Hypothesis $3(a-c)$ : Those who are more (a) extraverted and (b) proactive will be more attracted to organizations strong in the Dominance dimension. Specifically, preference for the Dominance dimension will be correlated with (a) Extraversion and (b) Proactivity.

The Thrift dimension. The adjectives used to describe organizations perceived to be high on the Thrift dimension are low budget, low class, simple, reduced, sloppy, poor, undersized, and deprived. K-Mart, Kroger, Wal-Mart, Subway, Bob Evans, Meijer, and J.C. Penney are all examples of firms that are described by this dimension (Slaughter \& Greguras, 2009). The Thrift dimension has only been demonstrated to show negative relationships with attractiveness (Slaughter et al., 2004; Slaughter \& Greguras). Therefore, the Thrift dimension is only expected to have negative relationships with the Big Five dimensions. The Thrift dimension is perceived as low class, low budget, and simple; therefore the people who work there are perceived to be the same. For this reason individuals that are ambitious (i.e. conscientious), sociable (i.e. extraverted), and team-oriented (i.e. agreeable) may find these organizations less attractive. Hypothesis $4(a-c)$ : Those who are more (a) conscientious, (b) extraverted and (c) agreeable will be less attracted to organizations strong in the Thrift dimension. Specifically, preference for the Thrift dimension will be negatively correlated with (a) Conscientiousness, (b) Extraversion and (c) Agreeableness. 
The Style dimension. The adjectives used to describe organizations perceived to be high on the Style dimension are stylish, fashionable, hip, and trendy. Nike, Reebok, Pepsi, and Motorola are examples of firms that are described by this dimension (Slaughter \& Greguras, 2009). Individuals that are attracted to this dimension will prefer organizations that define style and create popular culture. These individuals will likely be creative, artistic, open-minded, and cultured (i.e., open to experience) and prefer organizations where they will have the opportunity to be creative and explore new ideas.

Hypothesis 5: Those who are more open to experience will be more attracted to organizations strong in the Style dimension. Specifically, preference for the Style dimension will be correlated with Openness to Experience.

Method

\section{Sample and Procedure}

All participants were recruited from undergraduate psychology or communications studies courses at a large university in the northwestern United States. Participants were provided with course credit. All data collection took place during the beginning of regularly scheduled class time. A total of 70 participated in the study. The study included 41 women and was $73 \%$ White. Sixty-six percent of the sample was currently employed, and $100 \%$ had some employment experience.

Data were collected from a single survey. The survey first asked participants to rate the attractiveness of personality trait adjectives for their ideal organization. Next, participants were asked to complete a measure of their proactive personality and Big Five personality. Finally individual demographics were collected. 
Note that Slaughter and Greguras (2009) point out that there is good reason for sampling from participants who are not actively engaged in the job seeking process (e.g. those enrolled in college). It is likely that these participants will be more idealistic when conceiving of their ideal employer, and subsequently they may have the greatest interest in finding a company that matches their ideals. For this reason I was interested in university students.

Measures

Organization personality perceptions. Organization personality perceptions of the ideal employer were measured using a 33-item scale developed by Slaughter et al. (2004). This measure is used to describe organizational personality and capture the structure of organization personality perceptions. On a Likert scale of 1-5 (1= strongly disagree; 5 = strongly agree) participants were asked rate to the degree to which the 33 organizational personality trait adjectives described their ideal employer. These 33 traits are categorized into five organizational personality types: Boy Scout, Innovativeness, Dominance, Thrift, and Style. Examples of the adjectives were friendly (9 items; Boy Scout; $\alpha=.86$ ), exciting (7 items; Innovativeness; $\alpha=$ .83 ), successful (5 items; Dominance; $\alpha=.73$ ), simple (8 items; Thrift; $\alpha=.78$ ), and hip (4 items; Style; $\alpha=.95$ ).

Proactive personality. I used a 10-item proactive personality scale developed by Siebert et al. (1999). The scale is a shortened version of the original 17-item Proactive Personality Scale (PPS) developed by Bateman and Crant (1993). The scale used in this study asked participants to rate their agreement ( 1 = strongly disagree; 7 = strongly agree) on the degree to which the ten statements described them personally. Examples of the statements were "if I see something I don’t like, I fix it,” and “I excel at identifying opportunities.” Alpha for the scale was .87. 
Big Five personality. Big Five personality was measured using the Ten-Item Personality Inventory (TIPI) developed by Gosling et al. (2004). Participants were asked to rate their agreement ( 1 = strongly disagree; 7 = strongly agree) on the degree to which each of the 10 pairs of descriptors described them personally. The pairs were extroverted and enthusiastic (Extroversion; $\alpha=.59$ ), anxious and easily upset (Neuroticism; $\alpha=.65$ ), open to new experiences and complex (Openness to Experience; $\alpha=.23$ ), dependable and self-disciplined (Conscientiousness; $\alpha=.74$ ), and reserved and quiet (Agreeableness; $\alpha=.50$ ). Although most of these alphas were below the recommended .70, the internal consistency of Big Five measures is often low because of the breadth of each factor. In addition, only having two items lowers the reliability. As a result, if anything, this should lead to a conservative test of the hypotheses. Finally, because the Openness to Experience alpha is particularly low, I double-checked for coding errors, but found none. This low alpha is likely due to the breadth of the Openness to Experience factor.

Results

Table 1 shows the means, standard deviations, and intercorrelations among variables in the study.

Hypotheses 1-6 predicted the relationship between self-rated personality and the attractiveness of different organizational personalities. Below I will present the results for each hypothesized relationship.

Hypothesis 1 predicted that individuals who rated themselves as more (a) agreeable and (b) conscientious would find the Boy Scout dimension more attractive. Review of Table 1 reveals that the relationship between Agreeableness and attractiveness of the Boy Scout dimension was significant, and the relationship between Conscientiousness and the Boy Scout 
dimension was not significant. Therefore, Hypothesis 1a was supported, and Hypothesis 1b was not supported.

Hypothesis 2 predicted that preference for the Innovativeness dimension of organizational personality would be correlated with (a) Conscientiousness, (b) Openness to Experience and (c) Proactivity. Table 1 shows that both Conscientiousness and Proactivity were not related to attractiveness of the Innovativeness dimension. Thus, Hypotheses 2a and 2c were not supported. However, the relationship between Openness to Experience and preference for Innovativeness dimension was significant. Therefore, Hypothesis $2 \mathrm{~b}$ was supported.

Hypothesis 3 predicted that individuals rating themselves as more (a) extraverted and (b) proactive would be more attracted to organizations described by the Dominance dimension of organizational personality. As shown in Table 1, there is a significant relationship between both Extraversion and Proactivity and attractiveness of the Dominance dimension. Therefore, Hypothesis 3 was supported.

Hypothesis 4 predicted that individuals who rated themselves as (a) conscientious, (b) extraverted and (c) agreeable would be less attracted to organizations described by the Thrift dimension of organizational personality. As predicted, Table 1 shows both Conscientiousness and Extraversion were negatively correlated with preference for the Thrift dimension. Thus, Hypothesis 4a and 4b were supported. The relationship between Agreeableness and the Thrift dimension was not significant. Therefore, Hypothesis 4c was not supported.

Hypothesis 5 predicted that preference for the Style dimension of organizational personality would be correlated with Openness to Experience. Review of Table 1 reveals that Openness to Experience is negatively correlated with the Style dimension. Thus, Hypothesis 5 was not supported. 
In addition, some other non-hypothesized relationships between human personality and the attractiveness of organizational personality types were found. As shown in Table 1, the Thrift dimension of organizational personality was negatively correlated with proactive personality, and the Style dimension was negatively correlated with Openness to Experience. Consistent with previous research (Bateman \& Crant, 1993), Table 1 also shows that Proactivity was correlated with both Extraversion and Conscientiousness.

\section{Discussion}

The purpose of this research was to examine the relationship between human personality and organizational personality types, in an attempt to determine which human personality types are most attracted to each organizational personality dimension. The results of the study show several significant relationships.

The relationships between human personality and organizational personality should be interpreted in two ways. First, organizations should market themselves in a way that reaches individuals characterized by the human personality dimensions that are related to their organizational personality type. For example, if an organization projects an image characterized by the Innovativeness dimension, they should expect to receive applicants that are high in Openness to Experience. Second, if an organization determines that they need applicants that are characterized by a particular human personality trait they should market themselves according to the organizational personality dimension that those individuals find most attractive. For example, if an organization needs individuals that are high in Proactivity they should portray an image characterized by the Dominance dimension.

Slaughter and Greguras (2009) have suggested that organizations characterized by the Thrift dimension need the most help in attracting applicants. As the results of this study, and all 
other published studies involving the Thrift dimension (Slaughter et al., 2004; Slaughter \& Greguras) demonstrate, applicants are generally not attracted to the Thrift dimension. In fact, the results of the present study showed that applicants who are proactive, conscientious, and extraverted - three important employee traits - actually find organizations characterized by Thrift to be less attractive. Therefore, organizations characterized by the Thrift dimension are in a position to gain the most from 'rebranding' their organizational personalities.

Future research should continue to evaluate the relationship between organization personality perceptions and human personality. Specifically, it would be helpful if future research were able to capture actual applicant behavior regarding actual organizations. It would be interesting to capture whether or not these relationships exist in the real world and if they lead to better employee-related outcomes (e.g. lower rates of turnover or higher productivity) after people are hired. One possible way to capture this behavior would be to sample from a job fair with a longitudinal design.

\section{Limitations}

This study was intended to be simple. The first limitation of this study is the use of simplified metrics. Although the TIPI was demonstrated to be valid (Gosling et al., 2004), the brevity of this measure may have lead to somewhat low reliability for the Big Five dimensions, especially Openness to Experience. Future studies should use more comprehensive measures of personality (e.g. Big Five facets). However, it is important to point out that the present study obtained significant results even with less reliable measures, suggesting that stronger relationships might be found in replications where more reliable measures are used.

Second, there could be some inflation of relationships as there was only single-source data measured at one time point. Future studies should involve multiple sampling intervals, and, 
as suggested previously, a longitudinal design would be the most informative, as it would capture the long-term effects.

Third, the sample was small ( $\mathrm{N}=70)$, predominantly female (59\%), white (73\%), currently working (66\%), all participants had prior work experience, and all students were from the same university and were studying the same two subjects. Future studies should include a larger and more diverse sample to see if this would in any way affect the results.

\section{Conclusion}

This research investigated the relationship between organization personality perceptions and human personality measured in terms of Big Five personality and proactive personality. Slaughter and Greguras (2009) have suggested that the link between human personality and initial attraction to organizations is determined, at least partially, by organization personality perceptions. Slaughter et al. (2004) have suggested that when job seekers are assessing their attractiveness to organizations they consider organizations in terms of the human characteristics associated with the company (e.g. organization personality perceptions), and that five organizational personality types categorize these characteristics. Cable and Turban (2001) have stated that attraction to organizations varies by the job seekers perception of the company. Human resources departments are the marketers of employment for organizations; they are responsible for supplying job seekers with information about the organization. When communicating with job seekers it is important to remember that individuals are drawn to situations that are similar to their self-concept (Schneider, 1987). Thus, recruiters should leverage their organizational personality to the types of applicants they are most interested in attracting. Moreover, human resources departments should assess their needs, then determine how to market their organization during recruitment. 


\section{References}

Aaker, D. A. (1991). Managing brand equity: Capitalizing on the value of a brand name. New York: Free Press.

Aaker, D. A. (1996). Building strong brands. New York: Free Press.

Aaker, J. L. (1997). Dimensions of brand personality. Journal of Marketing Research, 34, 347-356.

Barrick, M. R., \& Mount, M. K. (1991). The Big Five personality dimensions and job performance: A meta-analysis. Personnel Psychology, 44, 1-26.

Barrick, M. R., Mount, M. K., \& Judge, T. A. (2001). Personality and performance at the beginning of the new millennium: What do we know and where do we go next? International Journal of Selection and Assessment, 9, 9-30.

Barney, J. B. (1986). Organizational culture: Can it be a source of sustained competitive advantage? Academy of Management Review, 11, 656-665.

Bateman, T. S., \& Crant, J. M. (1993). The proactive component of organizational behavior: A measure and correlates. Journal of Organizational Behavior, 14,103-118.

Cable, D. M., \& Turban, D. B. (2001). Establishing the dimensions, sources, and value of job seekers’ employer knowledge during recruitment. Research in Personnel and Human Resources Management, 20,115-163.

Cable, D. M., \& Yu, K. Y. T. (2006). Managing job seekers' organizational image beliefs: The role of media richness and media credibility. Journal of Applied Psychology, 91, 828840.

Crant, J. M. (1995). The Proactive Personality Scale and objective job performance among real estate agents. Journal of Applied Psychology, 80, 532-537. 
Crant, J. M., \& Bateman, T. S. (2000). Charismatic leadership viewed from above: The impact of proactive personality. Journal of Organizational Behavior, 21, 63-75.

Devendorf, S. A., \& Highhouse, S. (2008). Applicant-employee similarity and attraction to an employer. Journal of Occupational and Organizational Psychology, 81, 607-617.

Gosling, S. D., Rentfrow, P. J., \& Swann, W. B. (2003). A very brief measure of the Big-Five personality domains. Journal of Research in Personality, 37, 504-528.

Kapferer, J. (2004). The new strategic brand management: Creating and sustaining brand equity long term. London: Kogan Page.

Keller, K. L. (1993). Conceptualizing, measuring, and managing customer-based brand equity. The Journal of Marketing, 57, 1-22.

Kotler, P. (1972). A generic concept of marketing. The Journal of Marketing, 36, 46-54.

Leonard, B. (1999). HR squeezed by tight labor market. HR Magazine, 44, 37.

Levy, P. E. (2006). Industrial/organizational psychology: Understanding the workplace. Boston: Houghton Mifflin.

McCrae, R. R. \& John, O. P. (1992). An introduction to the Five-Factor Model and its applications. Journal of Personality, 60, 175-215.

Rolland, J.P. (2002). Cross-cultural generalizability of the Five-Factor Model of personality. In McCrae, R. R. \& Allik, J. (Eds.), The Five-Factor Model of personality across cultures (p.7-28). New York: Kluwer Academic/Plenum Publishers.

Saucier, G. (1994) Mini-markers: A brief version of Goldbergs’s unipolar Big Five markers. Journal of Personality Assessment, 63, 506-516.

Schneider, B. (1987). The people make the place. Personnel Psychology, 40, 437-53. 
Seibert, S. E., Crant, J. M., \& Kraimer, M. L. (1999). Proactive personality and career success. The Journal of Applied Psychology, 84, 416-27.

Slaughter, J. E. \& Greguras, G. J. (2009). Initial attraction to organizations: The influence of trait inferences. International Journal of Selection and Assessment, 17, 1-18.

Slaughter, J. E., Zickar, M. J., Highhouse, S., \& Mohr, D. C. (2004). Personality trait inferences about organizations: Development of a measure and assessment of construct validity. Journal of Applied Psychology, 89, 85-103.

Sutin, A. R., Costa, P. T., Miech, R., \& Eaton, W. W. (2009). Personality and career success: Concurrent and longitudinal relations. European Journal of Personality, 23, 71-84. 
Table 1: Means, Standard Deviations, and Intercorrelations among Study Variables

\begin{tabular}{|c|c|c|c|c|c|c|c|c|c|c|c|c|c|}
\hline Variables & $\mathrm{M}$ & SD & 1 & 2 & 3 & 4 & 5 & 6 & 7 & 8 & 9 & 10 & 11 \\
\hline \multicolumn{14}{|l|}{ Human Personality } \\
\hline 1. Proactive & 5.15 & .730 & $(.866)$ & & & & & & & & & & \\
\hline \multicolumn{14}{|l|}{ Personality } \\
\hline 2. Openness to & 5.24 & .995 & $.254^{*}$ & $(.230)$ & & & & & & & & & \\
\hline \multicolumn{14}{|l|}{ Experience } \\
\hline 3. Conscientiousness & 5.56 & 1.18 & $.410 * *$ & $.256^{*}$ & $(.737)$ & & & & & & & & \\
\hline 4. Extraversion & 4.63 & 1.26 & $.404^{* *}$ & .158 & .100 & $(.593)$ & & & & & & & \\
\hline 5. Agreeableness & 3.31 & 1.19 & .221 & -.194 & -.170 & .077 & $(.498)$ & & & & & & \\
\hline 6. Neuroticism & 3.09 & 1.27 & .028 & -.224 & -.146 & -.043 & $.295 *$ & $(.646)$ & & & & & \\
\hline \multicolumn{14}{|c|}{ Organizational Personality } \\
\hline 7. Boy Scout & 4.28 & .525 & -.079 & .176 & .068 & .147 & $-.339 * *$ & -.009 & $(.860)$ & & & & \\
\hline 8. Innovativeness & 3.32 & .396 & .184 & $.263 *$ & .144 & .191 & -.161 & .178 & $.455^{* *}$ & $(.828)$ & & & \\
\hline 9. Dominance & 4.68 & .713 & $.283^{*}$ & -.185 & .064 & $.277^{*}$ & .099 & .008 & $.295^{*}$ & $.335^{* *}$ & $(.725)$ & & \\
\hline 10. Thrift & 1.87 & .519 & $-.302 *$ & .085 & $-.316 * *$ & $-.334 * *$ & .155 & .030 & -.149 & $-.292 *$ & $-.364 * *$ & $(.796)$ & \\
\hline 11. Style & 3.23 & .919 & .147 & $-.253 *$ & .005 & .065 & -.061 & -.042 & .088 & .210 & $.430 * *$ & $-.286^{*}$ & $(.952)$ \\
\hline
\end{tabular}

$\mathrm{N}=66-70$

* Correlation is significant at the 0.05 level (2-tailed). ** Correlation is significant at the 0.01 level (2-tailed). 